\title{
A Tongue-like Projection of the Left Lobe in Human Liver, Accompanied with Lienorenal Venous Shunt and Intrahepatic Arterial Anastomosis
}

\author{
By \\ Shoji CHIBA, Takao SUZUKI and Tatsuo KASAI \\ Second Department of Anatomy, School of Medicine, Hirosaki University \\ 5, Zaifucho, Hirosaki, Aomori 036, Japan \\ -Received for Publication, February 21, 1991-
}

Key Words: Riedel's lobe, Lienorenal shunt, Intrahepatic anastomosis, Hepatic segmentation, Human

\begin{abstract}
Summary: The characteristic features of a tongue-like projection of the left lobe of the liver in a female adult, accompanied with a large lienorenal venous shunt and an intrahepatic anastomosis of the hepatic arteries, are described. By dissecting the liver parenchyma, this projection is supplied by a set of the lateral segmental branches of the portal vein, hepatic artery and hepatic ducts and by the branch of the left hepatic vein. The boundary between the abnormal and the proper left lobes can not be confirmed accurately, because the tongue-like projection is overlapped with the paraumbilical lobe on the visceral surface. However, the position is estimated a transverse line superior to the attachment to the proper left lobe. The anomaly is derived from a medial and inferior portion of the left lobe of the liver and may be regarded as a left half of the central lobe in the ape etiologically. No evidences to justify the co-existence of the tongue-like projection with the lienorenal shunt are confirmed.
\end{abstract}

The shapes of the human liver are changed variously by the mechanical stimuli of the diaphragm, ribs and abdominal viscera during the intra-uterine or after-birth circumstances (Burlet, 1910a; Siwe, 1937), while its congenital abnormalities are comparatively rare (Gray and Skandalakis, 1972; Arey, 1974). A possibility of the presence of the abnormal liver, an unexplained abdominal mass, has to keep in mind, because it is mistaken for an enlargement of the spleen and the wandering kidney (Potter and Coffey, 1956; Feist and Lasser, 1959). Although CT scans are recently used for diagnosis and operation of the abdominal diseases, McAfee et al. (1965) who studied the features of the liver in a great number of cases did not observe such an anomaly as the present case.

A tongue-like projection of the right lobe, which is so-called the Riedel's lobe (1888), is more popular, while its appearance on the left is extremely rare and has previously been reported only by a few authors (Katagiri, 1942; Dick, 1951; Kato et al., 1961). According to them, this abnormality was considered to be an atavistic form of the human liver as the result of an enlargement of the left lobe observed in embryos and fetuses.

The present authors describe the appearances of the left tongue-like projection of the liver and review the previously reported cases, and then examine the intra- hepatic distribution of the hepatic veins and portal triads (portal vein, hepatic artery and hepatic ducts). Moreover, the appearances of the lienorenal shunt and the intrahepatic anastomosis of the hepatic arteries are also described.

\section{Material and Methods}

The tongue-like projection of the left lobe of the liver was found in a 78-year-old woman during a practice dissection at Hirosaki University in 1988. After the ordinary dissection, the liver was examined macroscopically to clarify the intrahepatic distribution of the portal triads and the hepatic veins. No any injuries at operation during life were found in the abdomen, aberrant adhesions with the parietal membrane were not observed in the abdominal cavity, and the stones were not found in the gall-bladder. The appearance of the liver seemed to be normal, but some small cysts were found on the outer surface of the liver. To examine the pathological changes in the liver and the gall-bladder, their sections were prepared by hematoxylin-eosin stain. 


\section{Observations}

\section{The tongue-like projection of the left lobe}

The tongue-like projection is $10 \mathrm{~cm}$ in length, $8 \mathrm{~cm}$ in width, and $2.5 \mathrm{~cm}$ in thickness, extending downwards from the inferior border of the left lobe to reach nearly the left side of the umbilicus. The size of the abnormal lobe is almost equal to that of the rest of the left lobe and a transverse furrow between the two is found on the anterior surface. The lesser curvature of a U-shaped stomach is in contact with the abnormal lobe and the superior part of the duodenum contacts with the visceral surface of the right lobe (Plate I, Fig. 1).

On the opposite side of the liver, there is a shallow fissure which runs transversely to the fissure for the ligamentum teres. The fissure, which was called the left interlober fissure (Burlet, 1910a; Ruge, 1913), arises from an abnormal deep notch dividing the inferior border of the left lobe into two parts (Plate II, Fig. 2). At the medial base of the tongue-like projection and between the left lobe and the fissure for the ligamentum teres, a small triangle lobe is separated by an obliquely ascending fissure. The ligamentum teres, being larger in size and having a somewhat wide cavity in its cutedge, is enveloped with the liver parenchyma. The caudate lobe shows almost the same size as that of the normal case, and the quadrate lobe is smaller.

The liver is supplied by two different hepatic arteries. One of them arises from the celiac trunk and is distributed to the abnormal projection, the proper left lobe and the medial portion of the right lobe which belongs to the medial hepatic segment of the left lobe under segmentation of the liver. The other, which is the socalled accessory right hepatic artery (Adachi, 1928; Michels, 1951), arises from the superior mesenteric artery and it passes behind the common bile duct and the portal vein to distribute to the right lobe and the gall-bladder (Figs. 3 and 6). The branching pattern of the hepatic arteries is classified into Group 8 of Type I (Adachi, 1928), Pattern C (Michels, 1953b) and Pattern MD (Miyaki, 1989).

Three main (right, middle and left) hepatic veins are shown in the superior part of the groove for the inferior vena cava, and three small veins for the caudate lobe and the posterior part of the right lobe are also observed in the course of the groove (Figs. 3 and 6). At the porta hepatis, the portal vein and the common hepatic duct divide into the right and left branches, respectively.

\section{Segmentation of the liver}

1) Intrahepatic distribution of the portal triads and hepatic veins

The intrahepatic distribution of the portal triads and the hepatic veins is examined on the parietal and visceral surfaces, by removing the liver parenchyma, remaining the margin of the liver undissected. The liver of the present case is divided into four compartments as that in normal cases (Gupta et al., 1977; Clemente, 1985), and the branches of the middle hepatic vein run along the borders of each hepatic segment. The portal triads are commonly surrounded by the connective tissue sheath not to separate each of the components (Fig. 4). After removal of the sheath (Fig. 5), the branches of the portal vein run superficially to the bile ducts, and the hepatic arteries are mainly inserted between the vein and the ducts from the porta hepatis to the peripheries of the liver, in accordance with the statements reported by Melnikoff (1924), Hjorstjö (1951) and Elias and Petty (1952).

The Cantlie's line (1897), a longitudinal plane which runs between the caudate lobe and the fossa for the gallbladder, divides into two of the right and left lobes of the liver, in accordance with the course of an intermediate branch of the middle hepatic vein. The right lobe is subdivided into the anterior and posterior hepatic segments by a right branch of the middle hepatic vein and a branch of the left hepatic vein. The left lobe is also subdivided into the lateral and medial hepatic segments by a left branch of the middle hepatic vein, which passes along the line connecting between the ligamenta venosum and teres. Every branch of the middle hepatic vein runs particularly along a border of the hepatic segments (Figs. 4 and 6).

The medial segment of the left lobe and the caudate lobe are situated between the left and intermediate branches of the middle hepatic vein. The medial segment is supplied by the medial segmental branches of the portal triads, and the caudate one is supplied by two sets of the portal triads except of the bile ducts, arising from the different origins immediately after bifurcation of the portal vein. The proper left lobe is supplied by the upper branches of the lateral segments of the portal triads. The middle branch of the lateral segmental veins is distributed to the para-umbilical lobe (Hasebe, 1914), which is located in contact with the medial hepatic segment, the tongue-like projection and left proper lobe (Figs. 5 and 6).

The tongue-like projection is largely supplied by the most caudal one of the lateral segmental branches of the portal vein. On the visceral surface, the border between the proper left lobe and the tongue-like projection is laid transversely about at the level of the origin of the middle branch of the lateral segmental veins. However, this border is not distinct, because the paraumbilical lobe overlappes the two lobes. The tonguelike projection is therefore formed by the union of a great part of the inferior and medial portions of the left lobe and a small part of the para-umbilical lobe.

2) Intrahepatic distribution of the hepatic artery

The right hepatic artery which arises from the superior mesenteric artery gives off two cystic arteries, 


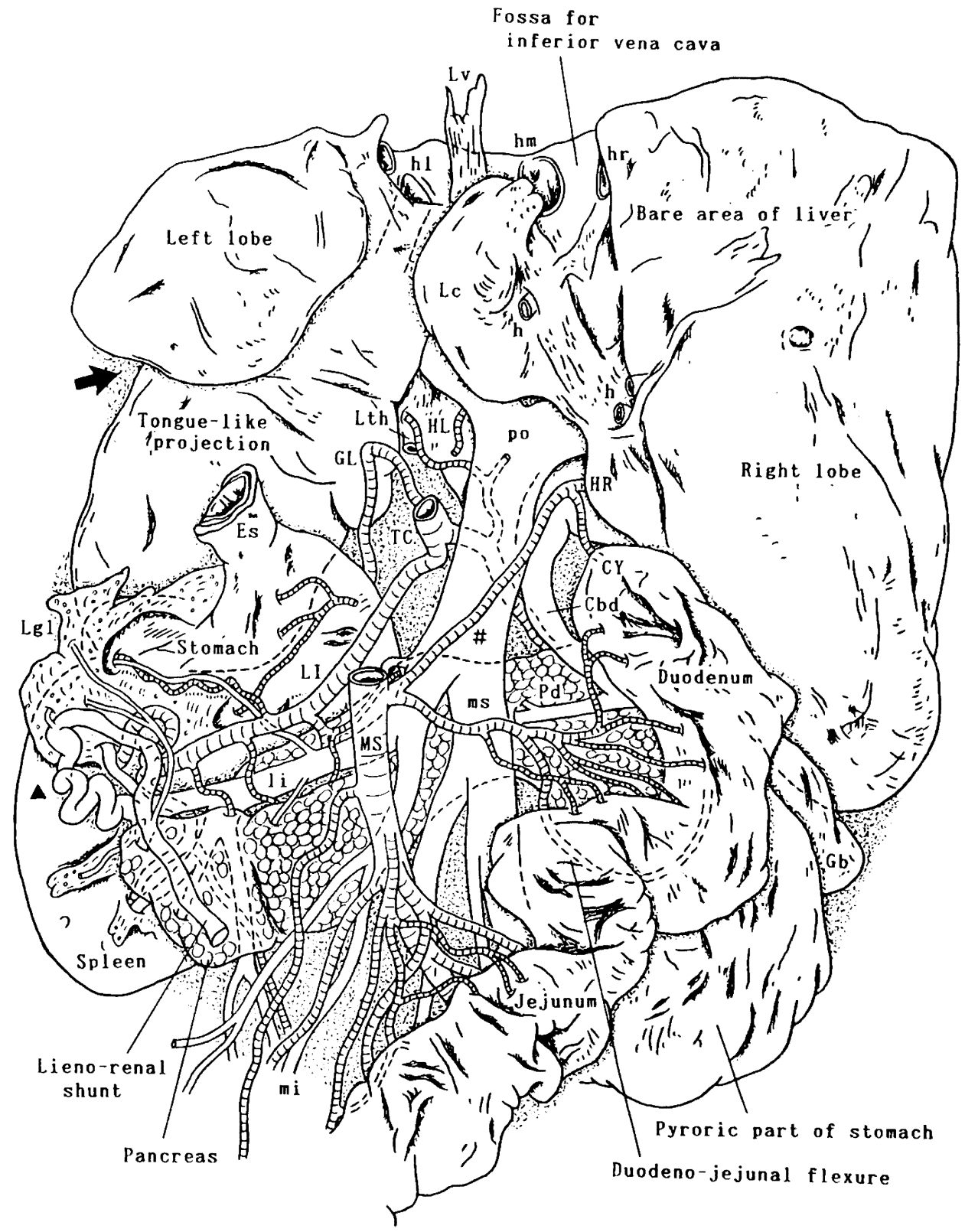

Fig. 3. A schematic drawing of the liver, the hepatic arteries and a tortously-coursed lienorenal shunt (marked by $\Delta$ ). Dorsal view.

The celiac trunk branched off the left hepatic arteries and the superior mesenteric artery gave off the cystic and the right accessory hepatic artery (marked by \#). The branching pattern of the arteries was belonged into Group 8 of Type I (Adachi, 1928) and into Pattern MD (Miyaki, 1989). In the groove for the inferior vena cava, three main hepatic veins and three small hepatic veins for the caudate and the right lobe were found.

Abbreviations for Figs. 1 $\sim 3$

Cbd: common bile duct

Es: esophagus

GL: left gastric artery

HL: left hepatic artery

$\mathrm{hm}$ : middle hepatic vein

HR: right hepatic artery

Lc: caudate lobe

LI: lienal artery

Lth: ligamentum teres hepatis

mi: inferior mesenteric vein

MS: superior mesenteric artery

Pd: main pancreatic duct

TC: celiac trunk
CY: cystic artery

Gb: gall-bladder

h: small hepatic veins

hl: left hepatic vein

hr: right hepatic vein

Lgl: gastro-lienal ligament

li: lienal vein

Lv: ligamentum venosum

ms: superior mesenteric vein

po: portal vein 


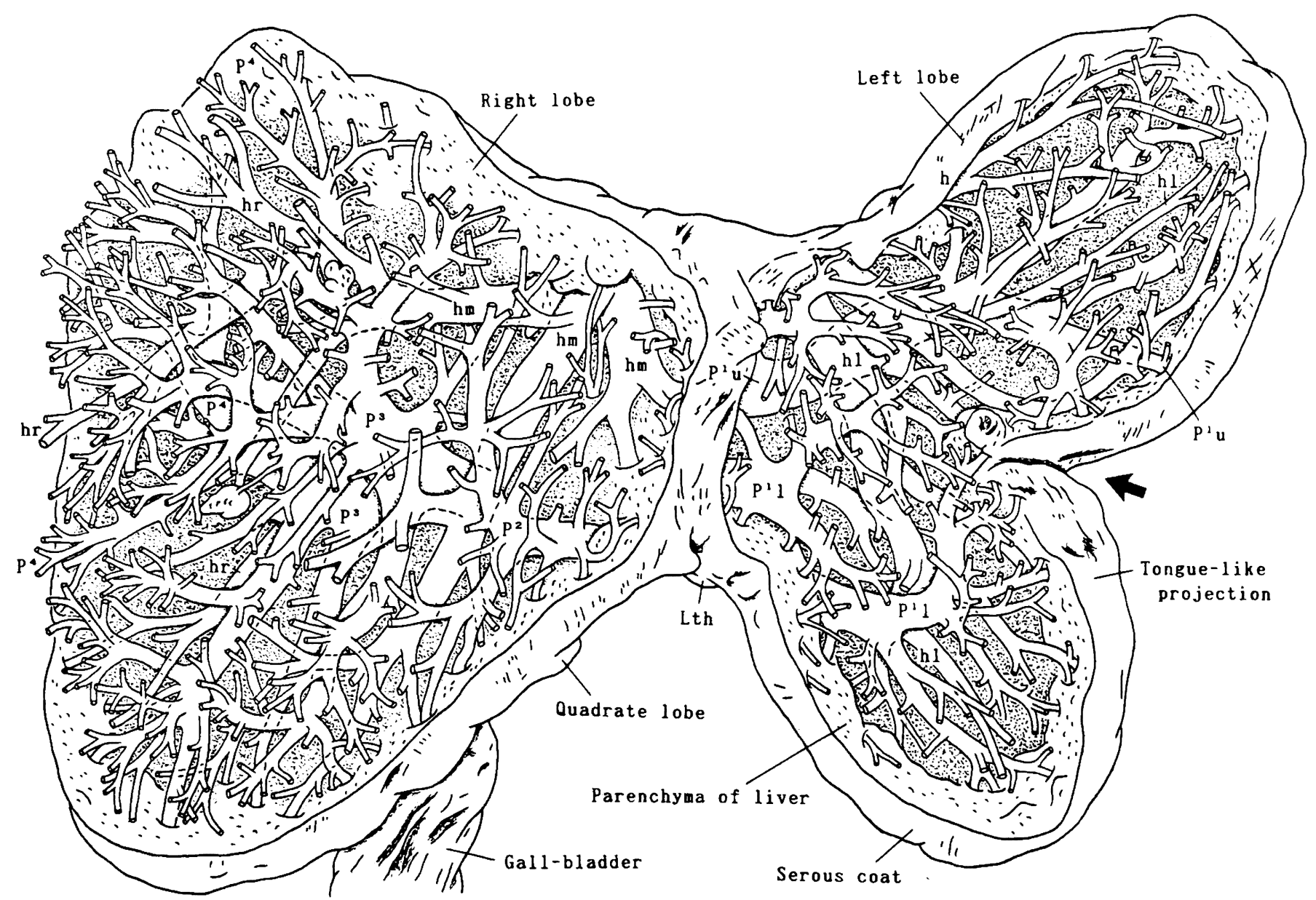

Fig. 4. Anterior view of the intrahepatic distribution of the hepatic veins and the portal triads enclosed in the connective tissue, without dissecting the margins of the liver. Some cysts were found in the peripheries of the bile ducts.

The tongue-like projection was supplied by two lower branches of the lateral segments of the portal triads and by the branch of the left hepatic vein. The border between the abnormal and proper left lobes was not shown accurately but was largely located at the region more superior to the attachment of the abnormal lobe.

\section{Abbreviations for Figs. $4 \sim 6$}

Cbd: common bile duct

CY: cystic artery

Hdl: left hepatic duct

hl: left hepatic vein

HR: right hepatic artery

Lth: ligamentum teres hepatis

po: portal vein
Chd: common hepatic duct

h: small hepatic veins

Hdr: right hepatic duct

$\mathrm{hm}$ : middle hepatic vein

hr: right hepatic vein

Lv: ligamentum venosum

$A^{1} \mathrm{u}$ : upper branch of the lateral segment of the left hepatic artery

$A^{1}$ : $\quad$ lower branch of the lateral segment of the left hepatic artery

$A^{2}$ : medial segment of the left hepatic artery

$A^{3}$ : anterior segment of the right hepatic artery

$A^{4}$ : posterior segment of the right hepatic artery

$B^{1} u$ : upper branch of the lateral segment of the left hepatic duct

$B^{1}$ : lower branch of the lateral segment of the left hepatic duct

$B^{2}$; medial segment of the left hepatic duct

$\mathrm{B}^{3}$ : anterior segment of the right hepatic duct

$B^{4}$ : posterior segment of the right hepatic duct

$\mathrm{B}^{\mathrm{c}}$ : biliary duct for the caudate lobe

$\mathrm{B}^{\mathrm{p}}$ : biliary duct for the para-umbilical lobe

$\mathrm{P}^{\mathrm{l}} \mathrm{u}$ : upper branch of the lateral segments of the portal vein

$\mathrm{P}^{1}$ : $\quad$ lower branches of the lateral segments of the portal vein

$\mathrm{P}^{2}$ : medial segment of the portal vein

$\mathrm{P}^{4}$ : posterior segment of the portal vein

$\mathrm{P}^{\mathrm{c}}$ : branches of the portal vein for the caudate lobe

$\mathrm{P}^{\mathrm{p}}$ : branch of the portal vein for the para-umbilical lobe 


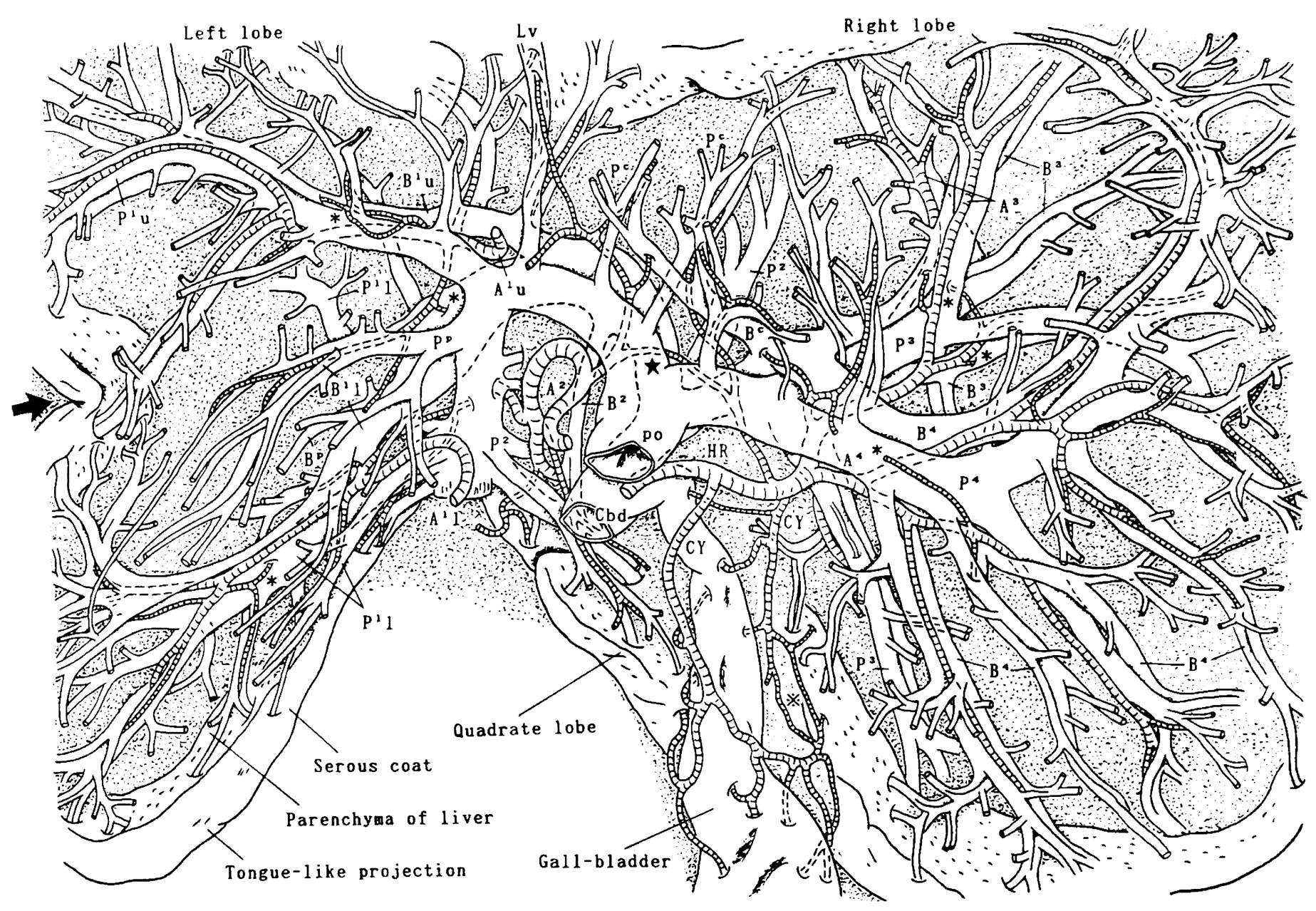

Fig. 5. Visceral view of the intrahepatic distribution of the portal triads except of the hepatic veins. Three left and one right cuts of the hepatic arteries were shown and the right hepatic artery branched off two cystic arteries to communicate with each other at the neck of the gall-bladder (marked by ※).

Being sandwiched in the portal vein and the hepatic ducts at the porta hepatis, the right and left arterial branches communicated with each other through an anastomosis of $1 \mathrm{~mm}$ in diameter (marked by $\star$ ), which were destined to supply the caudate lobe, the ligamentum venosum and the hepatic ducts.

The branches of the hepatic artery mainly ran as locating between those of the portal vein and the bile ducts. Number of the branches of the artery was estimated one or two in a set of the portal triads, and the nourish branches for the biliary ducts and portal vein (marked by $*$ ) were distinguished from the functional branches for the hepatic lobules. The former communicated with each other to form the arterial bypass of $0.2 \mathrm{~mm}$ in size around the portal vein and the bile ducts at the areas more peripherally than the point where the liver was divided into the four hepatic segments.

before dividing into the anterior and posterior segmental arteries. The cystic arteries communicate with each other and distribute to the gall-bladder and the visceral surface of the right lobe of the liver (Figs. 5 and 6). According to Michels (1951) and Netter (1964), two cystic arteries are found in $25 \%$ of the examined cases.

The left hepatic artery which arises from the celiac trunk divides into three branches. The first one, which is the so-called medial hepatic artery (Adachi, 1928; Michels, 1951), is distributed to the medial segment of the liver and a left half of the caudate lobe. The second one is distributed to the great part of the proper left lobe and the para-umbilical lobe, and the third one the anterior and basal part of the proper left lobe and the major part of the tongue-like projection (Fig. 6). The tongue-like projection is not separated clearly from the proper left lobe under the distribution of the portal triads. The caudate lobe is supplied by the branches arising from the right and left hepatic arteries, while the quadrate lobe is supplied by the first branch of the left hepatic artery.

Besides the functional arteries for the hepatic lobules, the nutritive arteries for the biliary ducts, blood vessels and connective tissue sheath are seen arising from the hepatic and segmental arteries. Around the portal vein and the biliary ducts, there are found the duplicated arteries; larger artery for function and nutrition of the hepatic lobules and smaller one for nutrition of the biliary ducts and blood vessels. The latter arteries communicate with each other to form arterial bypasses of $0.2 \mathrm{~mm}$ in diameter at some points more peripherally (Figs. 5 and 6, marked by asterisks).

An arcade of the hepatic artery, $1 \mathrm{~mm}$ in diameter, 


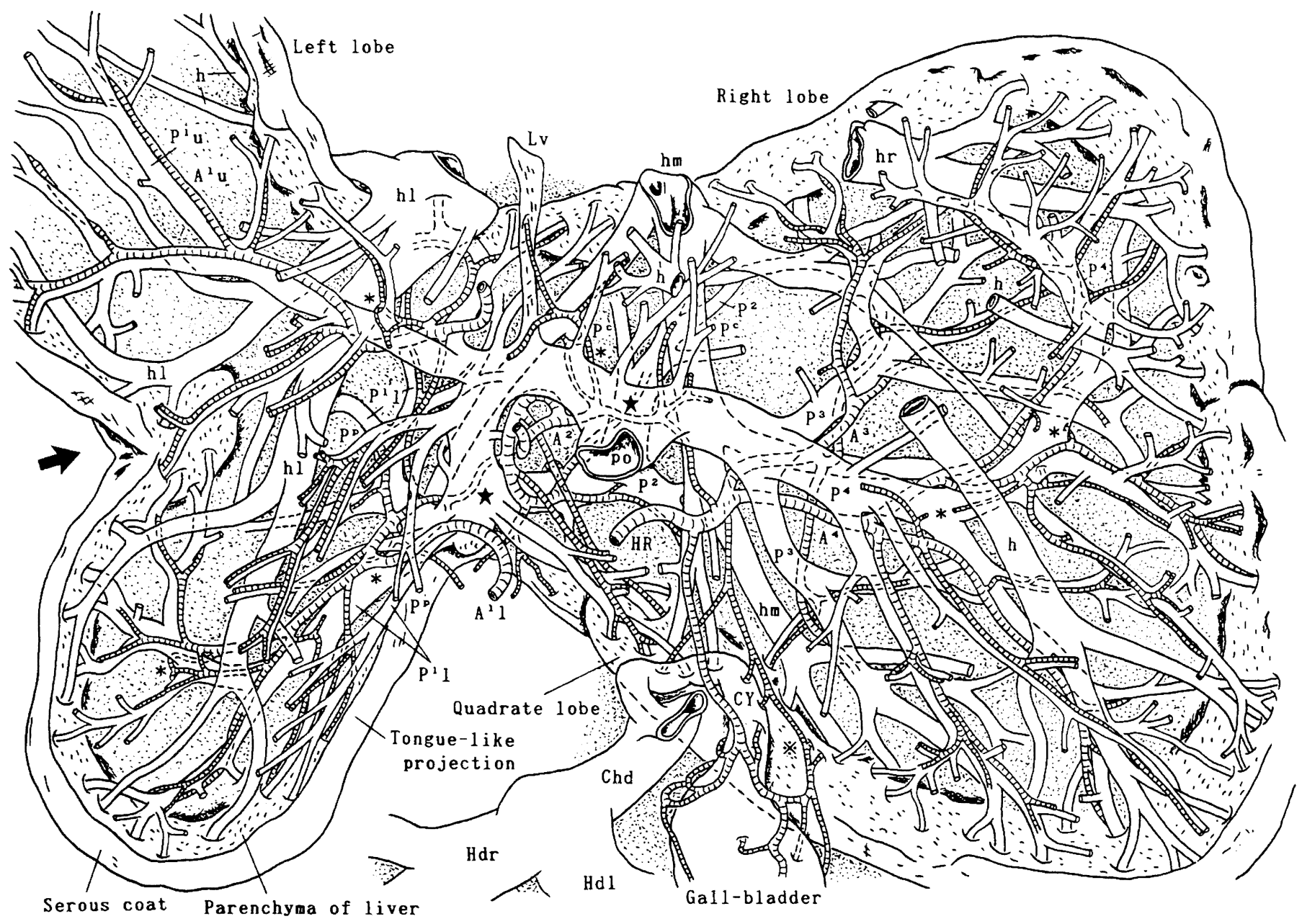

Fig. 6. Visceral view of the distributions of the portal triads and the hepatic veins, after removing the bile duct systems. The liver was divided into four main hepatic segments by each of the three branches of the middle hepatic vein.

The tongue-like projection was supplied by the branch of the left hepatic vein and by the lower branches of the lateral segments of the portal vein and the left hepatic arteries. The boundary between the tongue-like and proper left lobes could not define accurately, because the para-umbilical lobe overlapped the tongue-like projection on the visceral surface.

An intrahepatic arterial anasomosis of $1 \mathrm{~mm}$ in size, running behind the ligamentum teres to encircle it laterally, communicated between the two different branches of the left hepatic artery. This anastomosis also connected with another anastomosis observed behind the portal vein (marked by $\star$ ).

is formed along the portal vein, the transverse part of this vein and the ligamentum teres, and the arcade consists of two anastomoses. One of them connects the right hepatic artery with the first branch of the left hepatic artery through the branches for the caudate lobe and the ligamentum venosum. The other is found between the first and the second branches of the left hepatic artery beneath the ligamentum teres, partly embedded in the liver parenchyma (Figs. 5 and 6). The anastomoses, which are nutritive nature in function, are formed contacting with the hepatic ducts in and out of the porta hepatis, and they result in a large circle of the collateral pathway, connecting the abdominal aorta which takes two different origins of the hepatic arteries (Figs. 3, 6 and 9).

\section{The lienorenal shunt}

In the retro-peritoneal space, a large aberrant vein of $7 \mathrm{~mm}$ in diameter descends from the spleen, passing between the tail of the pancreas and the left suprarenal gland (Figs. 7 and 9). The vein drains into the left suprarenal vein at the point of conjunction with some small veins from the diaphragm. It runs straightly in the lower half of the course, but is tortous in the lienorenal ligament near the hilum of the spleen. The abnormal vein also collects some veins from the fundus of the stomach, after passing through the gastrolienal ligament (Fig. 3).

A connection between the aberrant and the splenic veins is found on the visceral surface of the splenic hilum through the ascending branch of the splenic vein, without penetrating the substance of the spleen (Fig. 8 ). The descending branch of the splenic vein collects blood from the anterior half of the spleen, the greater curvature of the stomach and the greater omentum.

Histologically, the tongue-like projection, the rest of the liver, the gall-bladder and the hepatic ducts are almost normal in structure by hematoxylin-eosin stain. 


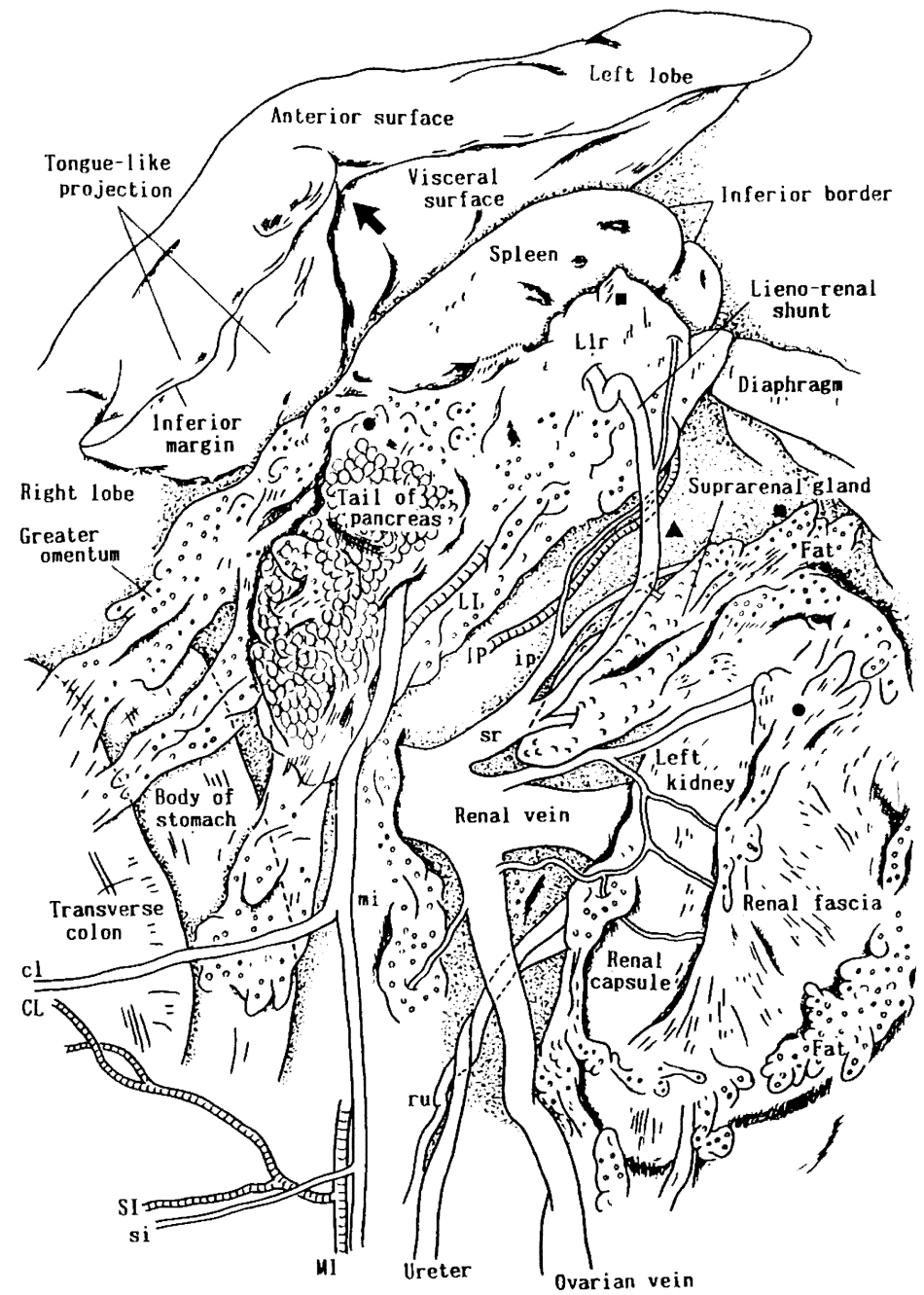

Fig. 7. Ventral view of the left kidney and the suprarenal gland enclosed in the adipose tissue, after turning over the tail of the pancreas and the spleen medially.

The abnormal vein, 6 or $7 \mathrm{~mm}$ in size, drained into the left renal vein under a common trunk with the suprarenal and inferior phrenic veins, after passing through the lieno-renal ligament (marked by $\Delta$ ). The two marks indicated the cuts of the lieno-renal ligament $(\square)$ and the overlying of the pancreas on the left kidney $(\bullet)$.

Abbreviations for Figs. 7 9

AA: abdominal aorta

CL: left colic artery

CY: cystic artery

EP: left gastro-epiploic artery

Gb: gall-bladder

HL: left hepatic artery

IP: inferior phrenic artery

LI: lienal artery

Llr: lieno-renal ligament

MI: inferior mesenteric artery

ov: ovarian vein

$\mathrm{Pa}$ : pancreas

ru: vein for the ureter

SI: sigmoid artery

sr: suprarenal vein

Ur: ureter
cl: left colic vein
Du: duodenum
ep: left gastro-epiploic vein

HR: right hepatic artery

ip: inferior phrenic vein

li: lienal vein

Lp: para-umbilical lobe

mi: inferior mesenteric vein

po: portal vein

rv: renal vein

si: $\quad$ sigmoid vein

vci: inferior vena cava

$A^{1} u$ : upper branch of the lateral segment of the left hepatic artery

$A^{1}$ : $\quad$ lower branch of the lateral segment of the left hepatic artery

$A^{2}$ : medial segment of the left hepatic artery

$A^{3}$ : anterior segment of the right hepatic artery

$\mathrm{A}^{4}$ : posterior segment of the right hepatic artery

L1, L3: first and third lumbar vertebrae 


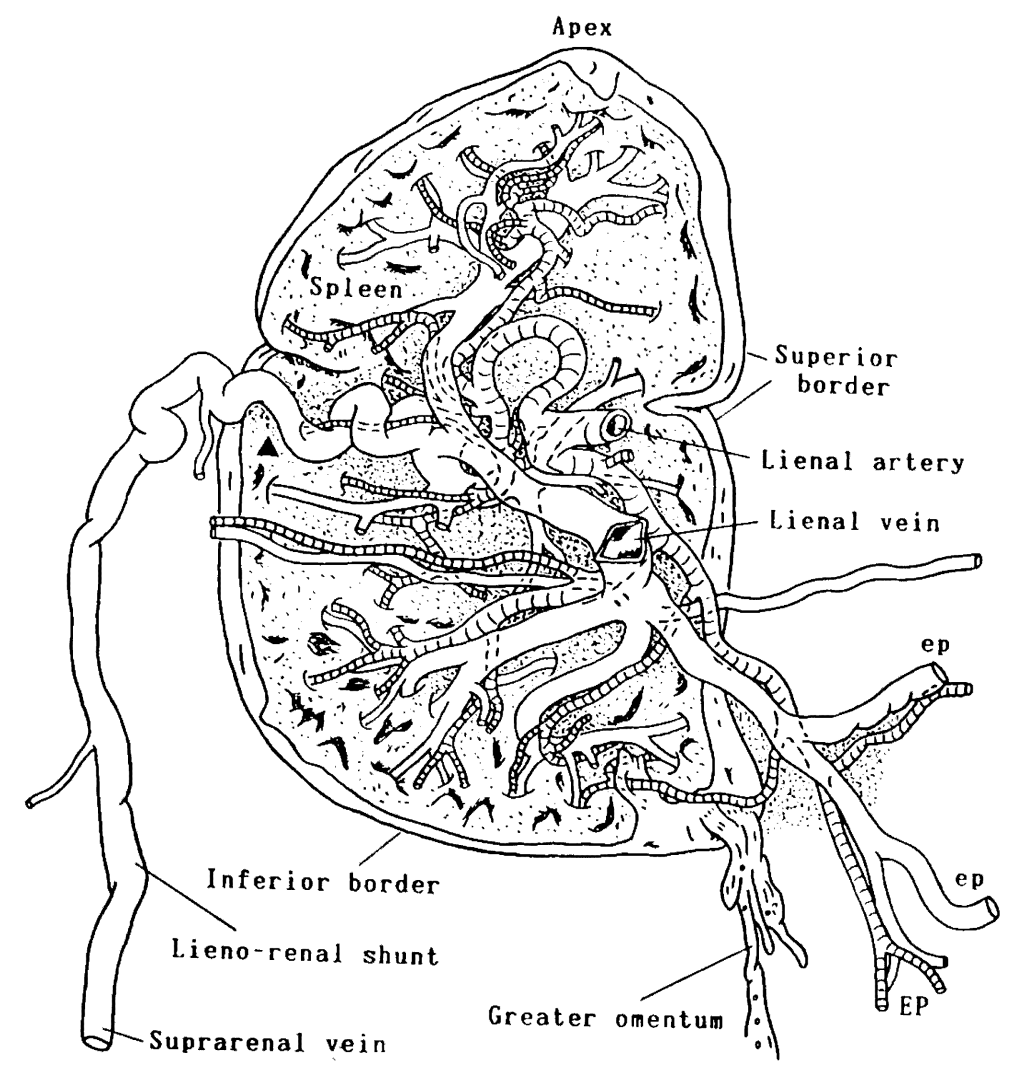

Fig. 8. Schematic drawing of the lienorenal shunt, after dissecting the blood vessels of the spleen. The aberrant vein (marked by $\mathbf{\Delta}$ ) ran tortously through the lienorenal ligament upwards and communicated with the ascending branch of the lienal vein at the hilus of the spleen.

\section{Discussion}

1. The left tongue-like projection of the liver

1) Cases of the tongue-like projection and the interlobar fissures

Since Riedel (1888) first pointed out that the projection of the right lobe of the liver as downwards as the iliac crest was found only in women, this abnormality, so-called the Riedel's lobe, has been reported in autopsies and in clinics by many authors (Thomson, 1885; Lockwood, 1903; Cullen, 1925; Reitemeiner et al., 1958; Kakizaki et al., 1969; Clearfield, 1985). However, the left-sided Riedel's lobe has previously been reported only in a few papers.

As to the shape of the normal liver, Caroli et al. (1962), McAfee et al. (1965) and Mould (1972) classified it into 5, 12 and 6 types by using CT scans and scintigrams, and they could obtain some cases of the Riedel's lobe on the right side, not finding any cases on the left side. Hasebe (1914) and Kudo $(1922,1923)$ could not obtain such an abnormality as the present case.

The tongue-like projection from the left lobe has been reported by the following authors. Katagiri (1942) described a case of a 67-year-old female, in which the left interlobar fissure was found and the caudal tip of the projection reached the level of the third lumbar vertebra. Dick (1951) reported a case. Reis et al. (1956) reported an appendicular lobe attached to the left lobe of a 2-year-old boy, combined with a bifurcate kidney and double ureters. In a 72-year-old female reported by Kato et al. (1961), the projections were found on both sides and the caudal tip of the right lobe reached the 4th lumbar vertebra, while the left lobe reached the 2nd lumbar. In this case, the stomach was abnormal in shape and the falciform ligament shifted abnormally to the right. Therefore, the present Riedel's lobe on the left side is the third case recorded in Japanese.

Barclay-Smith (1909) and Ruge (1913) stated that anomalous fissures in small extent and depth were more popular in the right lobe of the human liver but were extremely rare on the left, and that the fissures were more extensive in the fetuses or even in Simian as well as in ordinary mammalian livers except gorilla and human adults. Thomson (1898/99) also pointed that such fissures were constant in human fetal livers. Burlet (1910a) first described the name of the left interlobar fissure which arose from the umbilical fissure and divided the left lobe into the main and lateral appendicular parts in 23- and 33-mm human fetuses, and he also found it in the liver of a 8-month fetus (1910b). Such fissures were recorded in a 16-year-old youth by Parsons (1904), in a 63-year-old male by Bolk (1902), in one adult case by Naegeli (1912) and in three cases of 21-, 65- and 52-year-old males by Ruge (1910, 1913, 1917). According to the above-mentioned authors and Elze (1956), the fissures were considered to be the 
atavistic form which happened in early stage of the liver development.

The right and left lobes in the human liver were almost equal in size at an early stage of development (Ruge, 1913; Melenikoff, 1924; England, 1983; Honda, 1986). Owing to a relatively slow growth or an actual atrophy of the left lobe (Barclay-Smith, 1909; Arey, 1974) as well as the suppression of the blood flow in the left umbilical vein (Elias and Petty, 1952), the left lobe in adult might be smaller in size, as compared with that in the embryo and fetus. Katagiri (1942) and Kato et al. (1961) also stated that the left lobe of a normal liver began to degenerate at the late period of fetus and the abnormality resulted from depression of the degeneration.

According to Bradley (1909) and Pollack and Burton (1953), the mammalian livers usually consisted of one central and two lateral lobes, and the central lobe was developed along the umbilical veins, while the right and left lobes along the corresponding omphalomesenteric veins. The lateral lobes were connected with the right and left hepatic veins respectively, and the median hepatic vein grew slow and was connected with the central lobe.

Lipchick and Schwarz (1967) and Keyloun and Pinkernell (1967) found the Riedel's lobe by radiographic methods, in which the right lobe was divided into two parts by degeneration of the hepatic tissues under the hepatic cirrhosis. Noda (discussed in Iwamura et al., 1973) also pointed that the left lobe was separated into two with a cover of membranous sheath, by a massive necrosis of the liver tissue under the hepatic cirrhosis.

The tongue-like projection of the left lobe was considered as a congenital anomaly, because the cirrhotic changes were not found in the liver of the present case. Concerning the genese of this case, the present authors suspected that it might be resulted from the maintenance of the primary form and size in normal development.

The small lobe of the left lobe at the base of the tongue-like projection, the para-umbilical lobe, was originated from the central lobe in mammalian liver and was found in a 15-mm embryo of the pig (Bradley, 1909). This was located in the anterior margin of the left central lobe near the umbilical fissure, and it usually appeared in lower apes but was rare in man (Ruge, 1910; Hasebe, 1914). Kudo (1922) found such a lobe in $2(1.3 \%)$ of 158 human adult livers and in $5(5.5 \%)$ of 91 human fetuses.

\section{2) Lobes and segments of the liver}

Concerning the hepatic lobes in mammalian and human livers, Siwe (1937) summarized the various nomenclatures used by different authors. Morphological similarity of the hepatic lobes among the mammalian livers was argued by Rex (1888), Bradley (1909) and Burlet (1910a), who discussed it on the basis of distribution of the hepatic arteries and portal vein. Rex (1888) pointed that the mammalian livers were constituted from six lobes and that the second derivations of the portal vein took a common pattern in the separated livers as well as the consolidated ones. Mall (1906) also described that a human liver consisted of six primary lobes in 5- and $6.5-\mathrm{mm}$ embryos and that each lobe coincided with those of the six lobes of the mammalian livers.

Ruge (1910), Thomson (1898/99) and Hasebe (1914) described that the human left lobe was formed by fusion of the left lobe and a part of the central lobe and this process was completely formed in anthropoids. In accordance with the interlobar fissure, Naegeli (1912) obtained the fibrous intrahepatic septum on each side of a normal adult liver and considered it might be generally disappeared during its normal development.

According to Elze (1956), it could not be decided whether a fissure of the adult liver was derived from the septum between the two lobes or from a rapid enlargement of the liver. When the fissure was originated from the process of the former, the derivatives of the hepatic vessels had their own territories within the liver and they did not overlap with the other territories. Bradley (1909) also pointed that the causes of fissures were not clear and that the umbilical fissure did not coincide with a true dividing line of the liver developmentally and morphologically, because of a possibility of preceding mesodermic septa which separated the lobes at an early embryo.

Although the Cantlie's line (1897) was considered as a longitudinal plane which divided the liver completely into two equal parts, Bradley (1909) indicated that the line was not determined scientifically but it was useful in practice. Moreover, Platzer and Maurer (1966) appointed that the position of the line was generally certified on the visceral surface of the liver but it was not determined easily on the outer surface, as having many varieties of the hepatic segmentation. Platzer and Maurer (1966) and Honda (1986) described that the lateral segment of the portal vein was divided into three branches in almost halves of the cases, and the intermediate branch could be discerned from the upper and lower ones, as supplying the para-umbilical lobe.

In comparison of the intrahepatic distribution of the portal triads and hepatic veins in the present case and the previously reported cases (Elias and Petty, 1952; Elze, 1956; Netter, 1964; Clemente, 1985), it was certain that the tongue-like projection, which was overlapped by the para-umbilical lobe on the visceral surface, was supplied by some lower branches of the lateral segments of the portal triads. Finally, the present authors concluded that the anomaly belonged to a part of the left lobe and also coincided with a remnant of the left- 


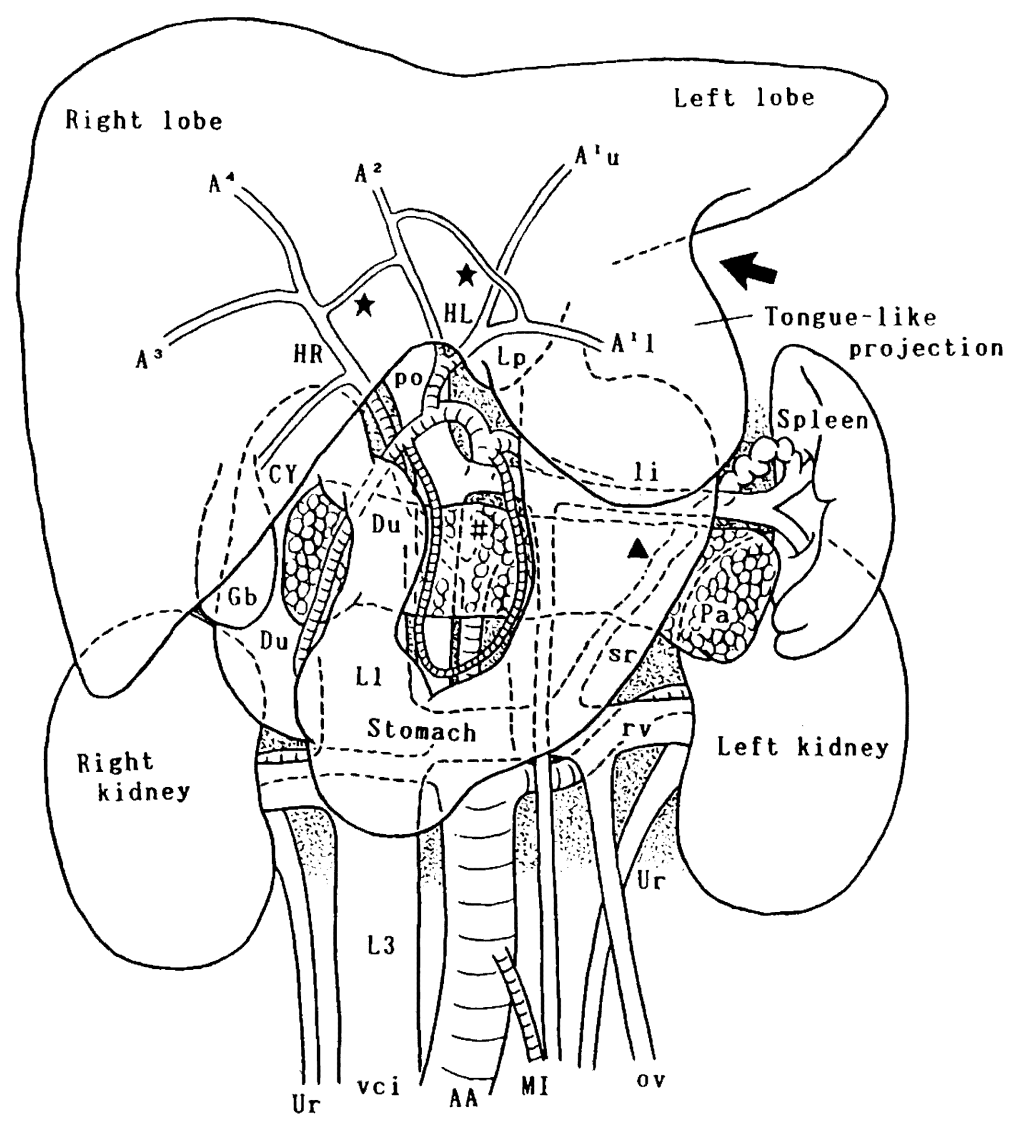

Fig. 9. Schematic drawing summarized the abnormalities in the present case: the tongue-like projection of the left lobe with a large notch at the inferior border (marked by the arrow) and the transverse interlobar furrows on both surfaces of the left lobe, the para-umbilical lobe at the medial base of the projection, the interhepatic arcade $(\star)$ formed by the two anasomoses of the right and left hepatic arteries, different origins of the hepatic arteries from the celiac trunk and the superior mesenteric artery (\#), the U-shaped stomach, and the lienorenal shunt $(\boldsymbol{\Delta})$ between the left suprarenal and lienal veins, running tortously beneath the pancreas.

half of the central lobe in apes (Figs. 9, 10 and 11).

2. The intrahepatic anastomosis of the hepatic arteries Origin and distributing pattern of the hepatic arteries were reported by Adachi (1928), Michels (1951, 1953a and b), Miyaki (1989) and others. However, the intrahepatic distribution of the hepatic arteries has been examined only by a few authors (Rex, 1888; Segall, 1923; Melnikoff, 1924; Hjortsjö, 1948; Elias and Petty, 1952; Healey and Sorensen, 1953).

Healey and Sorensen (1953) indicated that the socalled accessory hepatic artery, having a proper distribution area within the liver, did not communicate with the other hepatic arteries arising from the celiac trunk and that gross intrahepatic anastomoses were not observed among them. However, in $25 \%$ of the cases, small anastomotic channels between the right and left segments of the hepatic arteries existed at the porta hepatis and the umbilical fissure in the subcapsular and extrahepatic positions. Healey and Sorensen (1953) and Lichtman (1953) also pointed that the subcapsular branches, which were distributed in the fibrous sheath of the liver, communicated with the extrinsic arteries of the inferior phrenic artery at the fossa of the ligamentum venosum in most cases.
As to this problem, Tajiri (1960), by using the cast and Indian ink injection methods in the dog, human adult and fetal livers, ascertained that the wall of the bile ducts was supplied with the arterial network for themselves and that the subcapsular branches communicated with the hepatic arteries and the arteries of the bile ducts, the posterior abdominal wall and the retroperitoneal organs. Adachi (1928) also ascertained that the extrahepatic communications of $1 \mathrm{~mm}$ in size existed among the different branches of the hepatic arteries, passing along the common hepatic and bile ducts and the portal vein in the hepatoduodenal ligament. Melnikoff (1924), Hollinshead (1971) and Moore (1980) described the same.

In particular, Michels (1951) proposed a possibility that the minute arterial twigs for the bile ducts could be developed into a large artery to form a collateral pathway, when the major hepatic arteries were obstructed. Lichtman (1953) reported that the arterial network for the bile duct system was continuous in and out the liver. Parke et al. (1963) also indicated that a direct anastomotic channel was formed between the cystic and retroduodenal arteries through the epicholedochal arterial plexus on the common bile duct.

By using the roentgenopaque method in the human 


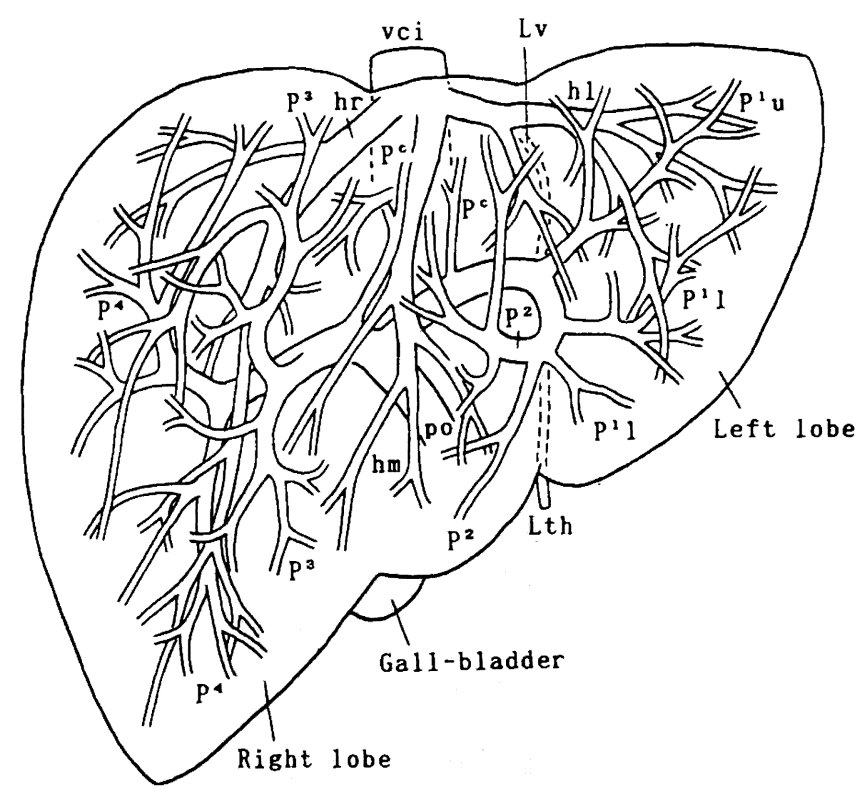

Fig. 10. Ventral view of the hepatic segments cited from Gray's Textbook (1985). The tongue-like projection of the present case was supplied by the lower branches of the lateral segments of the portal veins.

\section{Abbreviations for Figs. 10 and 11}

Cl:
Cr:
Ga:
hm:
Lc:
Lq:
Lth:

$\mathrm{P}^{1} \mathrm{u}$
$\mathrm{P}^{1}$ :
$\mathrm{P}^{2}$ :
$\mathrm{P}^{3}:$
$\mathrm{P}^{4}:$
$\mathrm{P}^{\mathrm{c}}$ :

left part of the central lobe right part of the central lobe gall-bladder middle hepatic vein caudate lobe quadrate lobe ligamentum teres hepatis

$\begin{array}{ll}\text { po: } & \text { portal vein } \\ \mathrm{hl}: & \text { left hepatic vein } \\ \mathrm{hr}: & \text { right hepatic vein } \\ \mathrm{Ll}: & \text { left lateral lobe } \\ \mathrm{Lr} & \text { right lateral lobe } \\ \mathrm{Lv}: & \text { ligamentum venosum } \\ \mathrm{vcl}: & \text { inferior vena cava }\end{array}$

vci: inferior vena cava

\footnotetext{
$\mathrm{P}^{1} \mathrm{u}$ : upper branch of the lateral segments of the portal vein

$\mathrm{P}^{1}$ l: $\quad$ lower branches of the lateral segments of the portal vein

$P^{2}$ : medial segment of the portal vein

$\mathrm{P}^{3}$ : anterior segment of the portal vein

$\mathrm{P}^{4}$ : $\quad$ posterior segment of the portal vein

$\mathrm{P}^{\mathrm{c}}$ : branches of the portal vein for the caudate lobe
}

liver, Glauser (1953) concluded that intrahepatic communications did not exist between the right and left hepatic arteries, and that all the anastomses were found in the hepatoduodenal ligament (lesser omentum) extrahepatically. Michels (1953b) revealed that the extrahepatic anastomoses between the major hepatic arteries were found frequently but the intrahepatic anastmoses were rare. However, Martens (1920) reported some cases in which the typical huge intra-hepatic arcade was formed between the right and left arterial branches.

The arterial arcade obtained in the present case was considered as a result of the communications between the intra- and extra-hepatic arteries for the bile duct, the portal vein and the ligamentum teres, after the subcapsular branch for the ligament being embedded in the hepatic tissue during the development. Although the hepatic artery was usually destined to the end-artery, it was true in the periphery of the liver but not true in the areas within a short distance from the divisions of the segmental branches of the hepatic artery.
3. The lienorenal shunt

The portal-systemic communications between the para-umbilical vein and the superficial veins of the subcutaneous fat in the abdomen were more popular than those between the splenic and renal veins. However, Edwards (1951) described that the portal vein usually communicated with the left renal vein in medium size of $2-3 \mathrm{~mm}$, and the communications contributed to the formation of the deep collateral pathways of the portal circulation. In normal adult, communications in the retroperitoneal area had an important role in collateral circulations, because the deep anastomoses were small in size but numerous in number. Such minute communications were frequently confirmed in adults by Gräsbeck (1927) and Sase (1929/30) and in children by Nadein and Krimholz (1926). Concerning the formation of the portal-systemic communications, Edwards (1951) considered it as the result from either 1) juxta-position of the visceral (vitelline vein) and systemic (subcardinal vein) vascular plexuses in embryo 

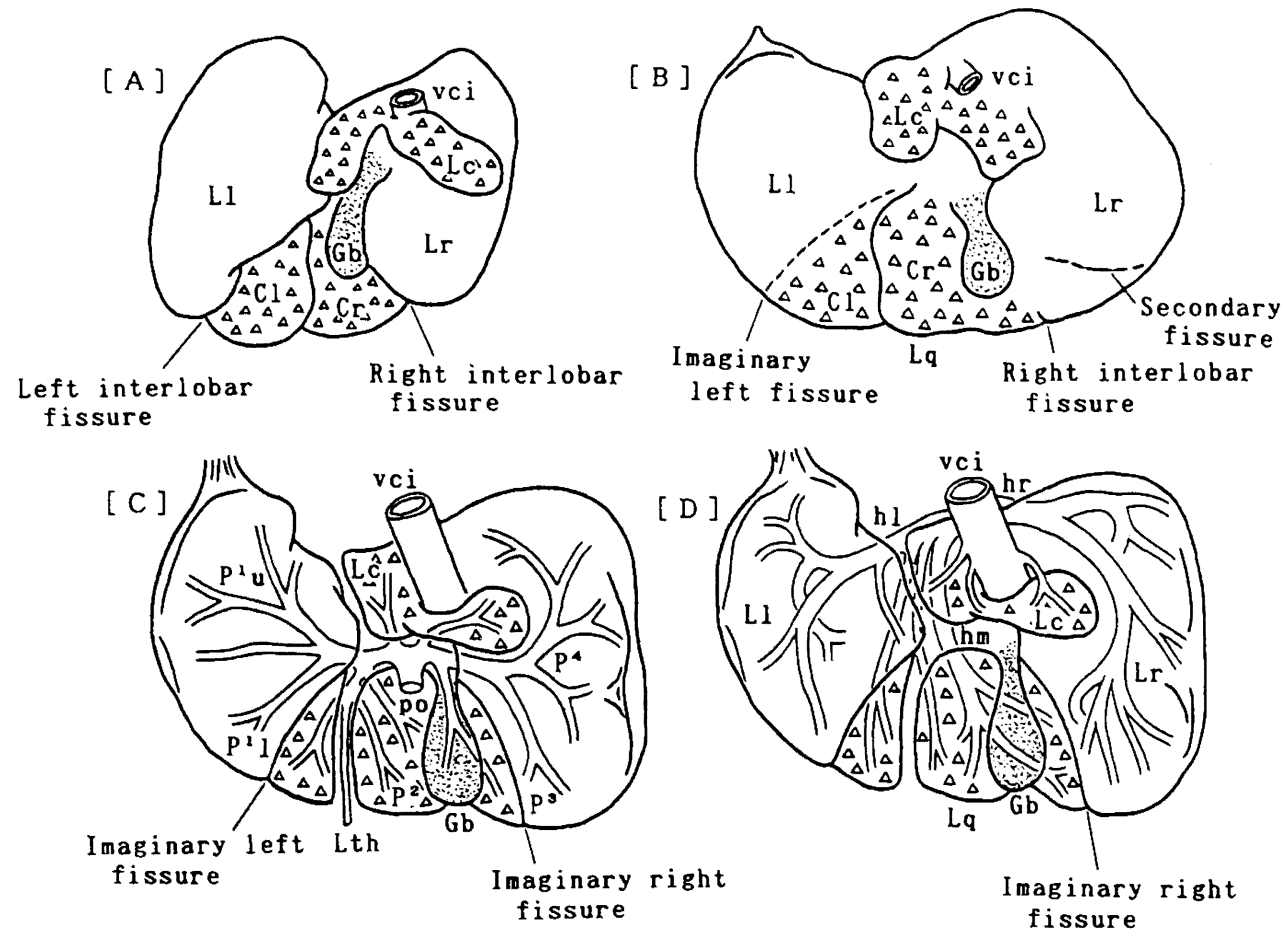

Fig. 11. Visceral views of the livers in an ape (Mac. cynomolgus, A) and in a 3-month human fetus (B), and those of intrahepatic distribution of the portal and hepatic veins in human adult (C and D), cited from Braus-Elze's Textbook (1956).

In general mammalians as well as the apes (A), the liver was consisted of one central and two right and left lateral lobes, and the central was subdivided into the right (quadrate and caudate) and left lobes.

The previous authors suspected that the human left lobe was formed by fusion of the left lobe and a left-half of the central lobe at the left interlobar fissure of the apes, and that the fissure was occasionally preserved in the human fetuses (B). The present tongue-like projection might be coincided with a remnant of the left-half of the ape's central lobe, as being an atavistic form of the human liver.

or 2) newly-formed fine venous communications during the period in which the visceral membrane of the gut fused with the posterior abdominal wall.

The lienorenal shunt more than $1 \mathrm{~cm}$ in size appeared by the stenosis of the portal vein, and the condition has been usually observed in hepatic cirrhosis or esophageal varicosis. Tsurumaru (1979) and Miyoshi et al. (1983) found the shunt in $12(12 \%)$ of 102 and in $6(9 \%)$ of 67 patients respectively with portal hypertension by portal angiography. Kinoshita (1953) narrowed the portal vein in dog and obtained the collateral pathways of the lienorenal shunt and the gastro-esophageal varicosis experimentally.

Anatomically, Miura (1897) reported a tortous, plexiform and large communication between the left ovarian and lienal veins in a 41-year-old woman, and Yamada (1934) also reported a large communication of $1.1 \mathrm{~cm}$ in size between the portal and left renal veins in a 60-year-old man. In the latter, the aberrant vein passed under the tail of the pancreas, the spleen and the fundus of the stomach to reach the left side of the vertebral column, and then took a course along the minor curvature of the stomach to drain into the portal vein. Mori (1952) described a direct large communication between the renal and lienal veins in a 46-year-old woman. Simonds (1936) found the anomalous largesized communication in one of his 160 cases $(0.6 \%)$ and summarized 7 cases reported in literatures.

The large-sized communication more than $1 \mathrm{~cm}$ was considered to be congenital and was rare in frequency (Edwards, 1951). According to Fischel (1929), an abnormal vein might be a remnant of the communications between the subcardinal and posterior cardinal veins, because the veins of the meso- and meta-nephric tissues had a great role in formation of the portal vein system in early development. On the other hand, Yamada (1934), Edwards (1951) and Mori (1952) suspected that the above-mentioned minute communications might be developed to form collateral pathways under the portal hypertension.

In the present case as well as the Mori's one, hepatic cirrhosis were not observed macroscopically on the surface of the liver, and the origin of the anomalous vein was considered as resulting either from an enlargement of the minute communications or from a remnant of the temporarily appeared communications in embryos.

Concerning the co-existence of the lienorenal shunt with the tongue-like projection of the left lobe of the liver, the present authors could not confirm the etiological geneses. 


\section{Acknowledgement}

The authors wish to express our sincere thanks to Dr. Y. Kamada, Assistant Professor of Hirosaki University School of Medicine, for his invaluable and friendly advices concerning the hepatic diseases.

\section{References}

1) Adachi, B.: Das Arteriensystem der Japaner. Bd. 2, 18-66, Verlag der Kaiserlich-Japanischen Universität zu Kyoto, Maruzen Co., Kyoto, 1928.

2) Arey, L.B.: Developmental Anatomy. 7th ed., 255-259, W.B. Saunders Co., Philadelphia, 1974.

3) Barclay-Smith, E.: A liver exhibiting multiple anomalies. J. Anat. \& Physiol., 43: 346-348, 1909.

4) Bolk, L.: Über die Persistenz fötaler Formerscheinungen bei einem erwachsenen Manne. Morph. Jahrb., 29: 78-84, 1902.

5) Bradley, O.C.: A contribution to the morphology and development of the mammalian liver. J. Anat. \& Physiol., 43: 1-42, 1909.

6) de Burlet, H.M.: Die äußeren Formverhältnisse der Leber beim menschlichen Embryo. Morph. Jahrb., 42: 1-71, 1910a.

7) de Burlet, H.M.: Zwei Fälle von abnormer Spaltbildung an der menschlichen Leber. Morph. Jahrb., 42: 477-483, $1910 \mathrm{~b}$.

8) Cantlie, J.: On a new arrangement of the right and left lobes of the liver. J. Anat. \& Physiol., 32: 4-9, 1897.

9) Caroli, J. and Bonneville, B.: Valeur diagnostique de la scintillographie hépatique. Arch. Mal. App. Digestif., 51: 55-82, 1962.

10) Clearfield, H.R.: Embryology, malformations, and malposition of the liver. In Bockus' Gastroenterology, Vol. 5, 4th ed., 2659-2665, W.B. Saunders, Philadelphia, 1985.

11) Clemente, C.D.: Gray's Anatomy, 30th ed., 1489-1498, Lea \& Febiger, Philadelphia, 1985.

12) Cullen, T.S.: Accessory lobes of the liver. Arch. Surg., 11: 718-764, 1925.

13) Dick, J.: Riedel's lobe and related parietal hepatic enlargements. Guy. Hosp. Rep., 100: 270-277, 1951. Cited from Gray and Skandalakis, 1972.

14) Edwards, E.A.: Functional anatomy of the porta-systemic communications. A.M.A. Arch. Intern. Med., 88: 137-154, 1951.

15) Elias, H. and Petty, D.: Gross anatomy of the blood vessels and ducts within the human liver. Amer. J. Anat., 90: 59-111, 1952.

16) Elze, C.: H. Braus' Anatomie des Menschen. Bd. 2, 3 Auf., 301-310, Springer-Verlag, Berlin, 1956.

17) England, M.A.: A Colour Atlas of Life Before Birth. 100-101, 128-131, Wolfe Medical Pub. Ltd., London, 1983.

18) Feist, J.H. and Lasser, E.C.: Identification of uncommon liver lobulations. J.A.M.A., 169: 1859-1862, 1959.

19) Fischel, A.: Lehrbuch der Entwicklung des Menschen. 729, Springer, Berlin, 1929. Cited from Yamada, 1934.

20) Glauser, F.: Studies on intrahepatic arterial circulation. Surgery, 33: 333-341, 1953.

21) Gräsbeck, A.: In der Blinddarmgegend vorkommende Anastomosen zwischen der Hohlvene und der Pfortader. Duodecim, 904-916, 1927. Cited from Anat. Bericht, 16: 212-213, 1929.

22) Gray, S.W. and Skandalakis, J.E.: Embryology for Surgeons. 217-224, W.B. Saunders Co., Philadelphia, 1972.

23) Gupta, S.C., Gupta, C.D. and Arora, A.K.: Subsegmentation of the human liver. J. Anat., 124: 413-423, 1977.

24) Hasebe, G.: A short report. 1. The shapes of the liver in
Japanese. Hokuetsu Igk. Z., 29: 47-56, 1914. (in Japanese).

25) Healey, J.E. and Sorensen, R.J.: The intrahepatic distribution of the hepatic artery in man. J. Intern. Coll. Surg., 20: 133-148, 1953.

26) Hjortsjö, C.H.: Die Anatomie der intrahepatischen Gallengänge beim Menschen, mittels Röntgen- und Injektionstechnik studiert, nebst Beiträgen zur Kenntnis der inner Lebertopographie. Kungl. Fysiogr., Sallskapets Handl., N.F., 59: 1-112, 1948. Cited from Healey et al., 1953.

27) Hjortsjö, C.H.: The topography of the intrahepatic duct systems. Acta Anat., 11: 599-615, 1951.

28) Hollinshead, W.H.: Anatomy for Surgeons. Vol. 2, 2nd ed., 314-380, 450-452, Harper \& Row, New York, 1971.

29) Honda, M.: Distribution of the portal vein in the liver of the Japanese fetus. J. Nippon Med. Sch., 53: 291-299, 1986. (in Japanese).

30) Iwamura, K., Yamanaka, I., Yamazaki, Y. and Shiroishi, I.: An anomaly of the left lobe of the liver, diagnosed as the splenoma by the liver scintigram (Abstract). J. Jap. Soc. Intern. Med., 62: 511, 1973. (in Japanese).

31) Kakizaki, Y., Ishiwatari, J., Fukushi, T., Okamoto, K., Toda, Y. and Tomita, S.: The position of the liver and its abnormalities. II. The abnormal lobes. Akita Med. J., 21: 46-53, 1969. (in Japanese).

32) Katagiri, Y.: An abnormal case of the liver having a large tongue-like projection on the left lobe of the liver. Hokuetsu Igk. Z., 57: 640-649, 1942. (in Japanese).

33) Kato, M., Okada, M., Sato, T. and Sebata, T.: A case of tongue-like process of the right and left lobes of the liver projecting downwards to reach the iliac crest. Report from The Department of Anatomy at Jikei University School of Medicine, 22: 1-4, 1961. (in Japanese).

34) Keyloun, V.E. and Pinkernell, B.: Riedel's lobe and cirrhosis. Amer. J. Digestive Dis., 12: 1174-1177, 1967.

35) Kinoshita, S.: Experimental and clinical studies on the portal hypertension and its roentgenographs. J. Nagoya Med. Ass., 69: 443-500, 1953. (in Japanese).

36) Kudo, T.: Abnormalities of the internal organs in human fetuses and adults as well as in primates ( 2 in the first report). Hokuetsu Igk. Z., 37: 465-501, 1922. (in Japanese).

37) Kudo, T.: Abnormalities of the internal organs in human fetuses and adults as well as in primates ( 3 in the first report). Hokuetsu Igk. Z., 38: 214-246, 1923. (in Japanese).

38) Lichtman, S.S.: Diseases of The Liver, Gallbladder and Bile Ducts. 3rd ed.,, Vol. 1, 17-45, Lea \& Febiger, Philadelphia, 1953.

39) Lipchik, E.O. and Schwartz, S.I.: Angiographic and scintillographic identification of Riedel's lobe of the liver. Radiology, 88: 48-50, 1967.

40) Lockwood, C.B.: Hepatectomy for the removal of Riedel's lobe. Lancet, 2: 223-224, 1903.

41) Mall, F.P.: A study of the structural unit of the liver. Amer. J. Anat., 5: 227-308, 1906. Cited from Bradley, 1909.

42) Martens, E.: Röntgenologische Studien zur arteriellen Gefässversorgung in der Leber. Arch. f. klin. Chir., 114: 1001-1012, 1920.

43) McAfee, J.G., Ause, R.G. and Wagner, H.N.: Diagnostic value of scintillation scanning of the liver. Arch. Intern. Med., 116: $95-110,1965$.

44) Melnikoff, A.: Arcitektur der intrahepatischen Gefässe und der Gallenwege des Menschen. Ztschr. Anat. und Entw., 70: 411-465, 1924.

45) Michels, N.A.: The hepatic, cystic and retroduodenal arteries and their relations to the biliary ducts. Ann. Surg., 133: 503-524, 1951.

46) Michels, N.A.: Variational anatomy of the hepatic, cystic and retroduodenal arteries; statistic analysis of their origin, distribu- 
tion, and relations to biliary ducts in 200 bodies. Arch. Surg., 66: 20-34, 1953a.

47) Michels, N.A.: Collateral arterial pathways to the liver after ligation of the hepatic artery and removal of the celiac axis. Cancer, 6: 708-724, 1953b.

48) Miura, M.: An abnormality of the vein. Zeitschr. d. TokioMed. Gesellsch., 11: 817-819, 872-874, 1897. (in Japanese).

49) Miyaki, T.: Patterns of arterial supply of the human fetal liver. Acta Anat., 136: 107-111, 1989.

50) Miyoshi, A., Ueki, T., Mano, M., Kuwahara, Y., Uraguchi, K., Nishida, H., Naito, H., Nakayama, Y., Nakayama, K. and Koga, M.: Studies on collaterals in portal hypertension based on these radiographic findings of percutaneous transhepatic portography. Jpn. J. Gastroenterol. Surg., 16: 1328-1333, 1983. (in Japanese).

51) Moore, K.L.: Clinically Oriented Anatomy. 209, Williams \& Wilkins, Baltimore, 1980.

52) Mori, T.: A case of anomalous connection between renal and lienal veins. Acta Anat. Nippon., 27: 100-102, 1952. (in Japanese).

54) Mould, R.F.: An investigation of the variations in normal liver shape. Br. J. Radiol., 45: 586-590, 1972.

55) Nadein, A.P. and Krimholz, M.L.: Die Collateralen des Portalsystems von vergleichend-anatomischem Gesichtspunkte. Kasansk. Med. J., 22: 263-267, 1926. Cited from Anat. Bericht, 8: $250,1927$.

56) Th. Naegeli: Bindegewebsseptum in der Leber eines Erwachsenen, der Rest einer Lappenspalte. Morph. Jahrb., 45: 193-197, 1912.

57) Netter, F.H.: The Ciba Collection of Medical Illustrations. Vol. 3, 2nd ed., 11-19, Ciba, New York, 1964.

58) Parke, W.W., Michels, N.A. and Ghosh, G.M.: Blood supply of the common bile duct. Surg. Gynec. \& Obst., 117: 47-55, 1963.

59) Parsons, F.G.: A liver in which there were two right and two left lobes. J. Anat. \& Physiol., 38: 23-24, 1904.

60) Platzer, W. and Maurer, H.: Zur Segmenteinteilung der Leber. Acta Anat., 63: 8-31, 1966.

61) Pollack, R.S. and Burton, S.D.: Accessory lobes of the liver. Calif. Med., 78: 520-521, 1953.

62) Potter, J. and Coffey, R.J.: Accessory lobe of the liver: Report of a case. Bull. Georgetown Univ. Med. Cen., 9: 162-164, 1956.

63) van der Reis, L., Clark, A.G. and McPhee, V.G.: Congenital
Hepatomegaly. Calif. Med., 85: 41-42, 1956.

64) Reitemeier, R.J., Butt, H.R. and Baggenstoss, A.H.: Riedel's lobe of the liver. Gastroenterology, 34: 1090-1095, 1958.

65) Rex, H.: Beiträge zur Morphologie der Säugerleber. Morph. Jahrb., 14: 517-617, 1888 .

66) Riedel, B.: Üeber den zungenförmigen Fortsatz des rechten Leberlappens und seine pathognostische Bedeutung für die Erkrankung der Gallenblase nebst Bemerkungen über Gallensteinoperationen. Berl. Klin. Wochenschr., 25: 577-581, 1888.

67) Ruge, G.: Die äu eren Formverhältnisse der Leber bei den Primaten. VI. Die Leber des Menschen (2. Fortsetung). Morph. Jahrb., 42: 361-476, 1910.

68) Ruge, G.: Abweichungen am linken Lappen der menschlichen Leber. Morph. Jahrb., 45: 409-430, 1913.

69) Ruge, G.: Spaltung des linken Lappens einer menschlichen Leber in einen Stamm- und Seitenlappen. Morph. Jahrb., 50: 345-350, 1917.

70) Sase, I.: On the communicating branches between the portal vein and the inferior vena cava enclosing their tributaries (Abstract). Acta Anat. Nippon., 2: 51-52, 1929/30. (in Japanese).

71) Segall, H.N.: An experimental investigation of the blood and bile channels of the liver. Surg. Gynec. \& Obst., 37: 152-178, 1923.

72) Simonds, J.P.: Chronic occlusion of the portal vein. Arch. Surg., 33: 397-424, 1936.

73) Siwe, S.A.: Die Großen Drüsen des Darmkanals. Die Leber, in L. Bolk's Handb. d. vergl. Anatomie III, 725-774, Urban \& Schwarzenberg, Berlin, 1937.

74) Tajiri, S.: The terminal distribution of the hepatic artery. Acta Med. Okayama, 14: 215-225, 1960.

75) Thomson, A.: Some variations in the anatomy of the human liver. J. Anat. \& Physiol., 19: 303-306, 1885.

76) Thomson, A.: The morphological significance of certain fissures in the human liver. J. Anat. \& Physiol., 33: 546-564, 1898/99.

77) Tsurumaru, M.: Studies on hepatofugal collaterals in portal hypertension. J. Jap. Surg. Soc., 80: 424-441, 1979. (in Japanese).

78) Yamada, S.: Über einen Fall von abnormer starker Anastomose zwischen der V. portae und der V. renalis sinistra. Acta Anat. Nippon., 7: 1088-1091, 1934. (in Japanese). 
Plate I

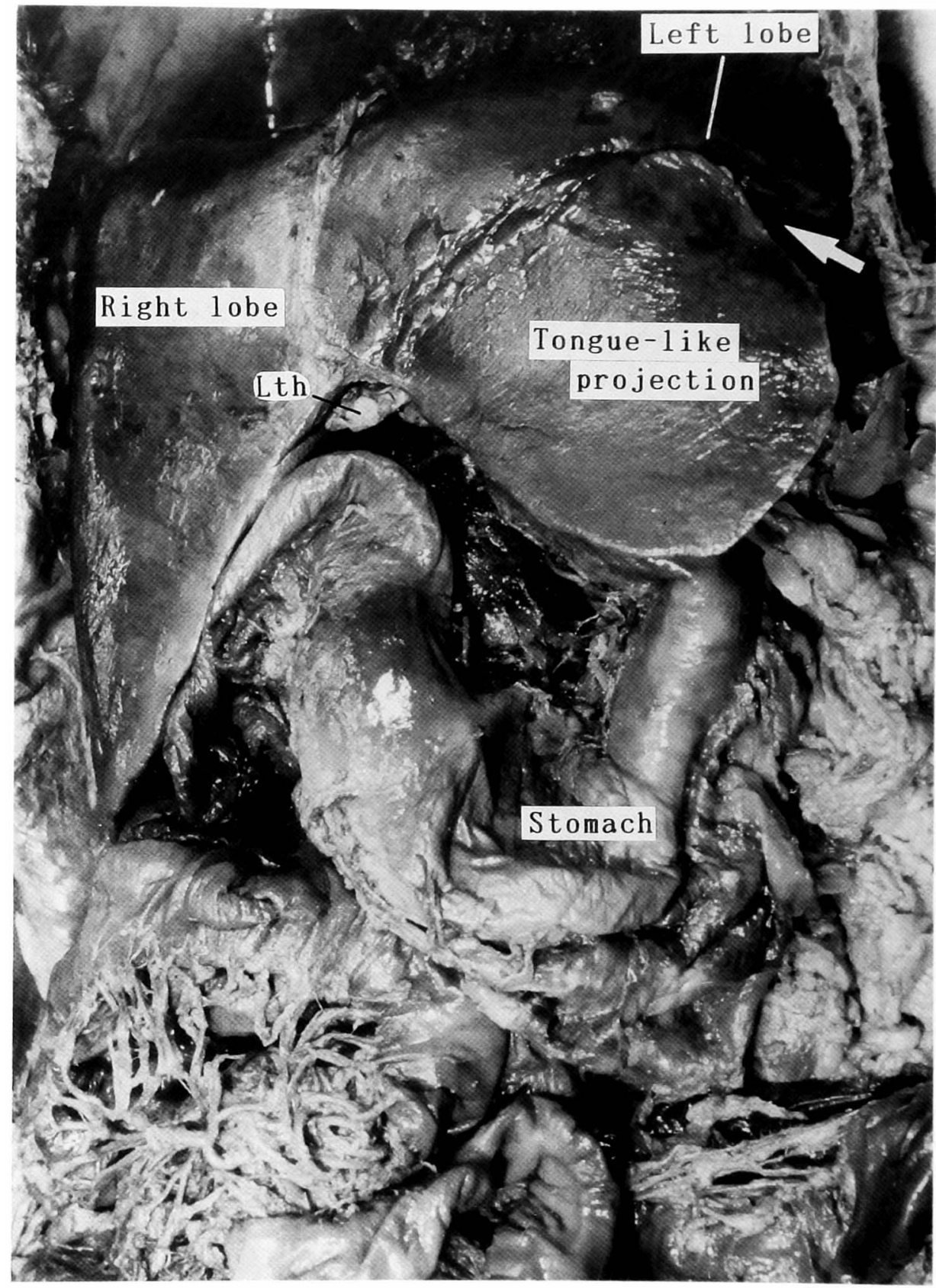

\section{Explanations for Figures}

Plate I

Fig. 1. A photograph of the tongue-like projection of the left lobe of the liver with a shallow transverse furrow, a large notch (marked by the white arrow) and a U-shaped stomach. Ventral view. 
Plate II

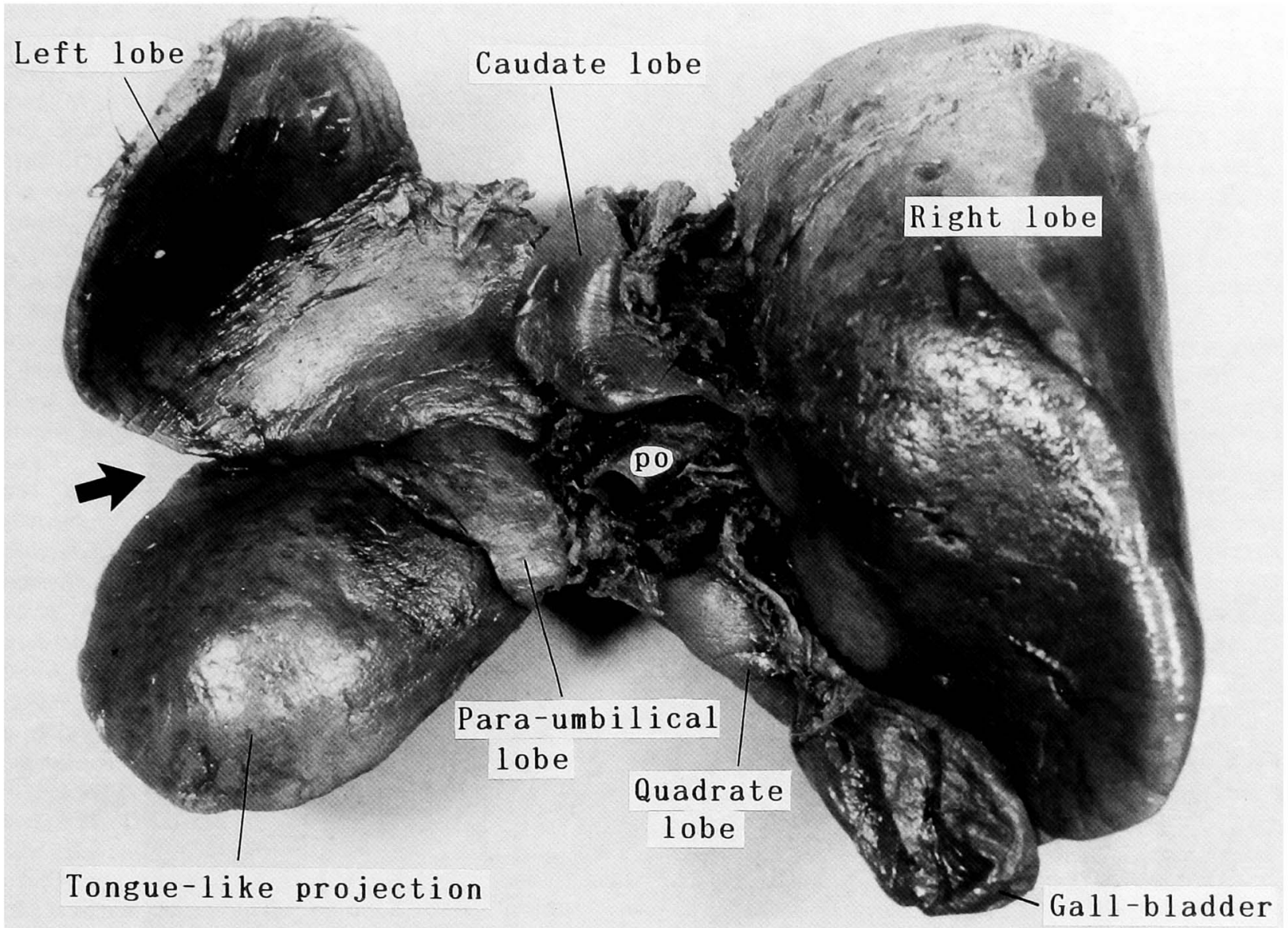

Plate II

Fig. 2. Visceral surface of the liver. On both surfaces, the transverse furrows were continued from a large notch (marked by the arrow) at the inferior border of the left lobe to divide it into two equal sizes, the tongue-like and the proper left lobes. At the base of the abnormal lobe, a small triangle lobe, the para-umbilical lobe, was separated by an oblique fissure near the ligamentum teres. 